\title{
Multi-Component Exercise Program and Improving Physical Performances in Older Inpatients: Results from A Pilot Interventional Study
}

\author{
V François*1, F Pamoukdjian², F Bruneau ${ }^{1}$, V Lévy ${ }^{3}$, C Bloch Queyrat ${ }^{3}$, M Boubaya ${ }^{3}$ and JJ Monsuez ${ }^{4}$ \\ ${ }^{1}$ Department of geriatric medicine, Rene Muret Hospital, France \\ ${ }^{2}$ Geriatric Department, APHP, Avicenne Hospital, France
}

${ }^{3}$ Avicenne Hospital, Clinical Research Unit and Clinical Research Center, France

${ }^{4}$ Department of cardiology, Rene Muret Hospital, France

*Corresponding author: Véronique François, APHP, Rene Muret Hospital, Department of geriatric medicine, France

\section{ARTICLE INFO \\ Received: 蔧 February 05, 2019 \\ Published: 蔧 February 13, 2019}

Citation: V François, F Pamoukdjian, F Bruneau, V Lévy, C Bloch Queyrat, M Boubaya, JJ Monsuez. Multi-Component Exercise Program and Improving Physical Performances in Older Inpatients: Results from A Pilot Interventional Study. Biomed J Sci \& Tech Res 14(3)-2019. BJSTR. MS.ID.002558.

Abbreviations: MCETP: Multi-Component Exercise Training Program; EWGOS: European Working Group on Sarcopenia; GA: Geriatric Assessment; CIRSG: Cumulative Illness Rating Scale Geriatric
ABSTRACT

Objectives: To assess the feasibility and the effects on physical performances of a multi-component exercise program (MCETP) in older inpatients.

Design and Setting: The training program included 3 components, endurance, balance, and resistance training. It consisted in 3 sessions per week during 3 months. Specifically, devoted strength-building machines were designed to properly fulfill the physical abilities of older people.

Participants: The program was proposed to 51 older hospitalized patients.

Measurements: Feasibility was assessed by recording the number of sessions the patients achieved, the occurrence of adverse events, the emotional response to training and subjective feeling of exertion-intensity, all items were recorded after each session. Physical performance changes were measured using the gait speed, the TUG and the chair rising ability.

Results: The 21 patients who refused the training had a significant lower MMSE than those who accepted. The body mass index of the 13 patients who completed a single session only was significantly higher. A total of 17 patients completed the entire training program. With the training, patients improved chair standing of 29\%, TUG of 33\% and gait speed of $50 \%$. No adverse effect or medical complication occurred. Patients completed $83 \%$ of the program. The causes for which sessions were missed were mainly due to simultaneous conventional hospital care or shortcomings. Sessions were perceived as hard for $0.3 \%$ of them, moderate for $33 \%$ and light for $67 \% .98 \%$ sessions were reported as pleasant.

Conclusion: In this preliminary study, a MCETP significantly improved physical performances of older inpatients after 12 weeks. These results have to be confirmed in a prospective, randomized controlled trial to follow.

\section{Introduction}

Frailty is an excess vulnerability to stressors, with a reduced ability to maintain or regain homeostasis after a destabilizing event, leading to poor outcomes: early death, disability, unplanned hospitalization and falls [1,2]. Frailty is a dynamic process, poten tially reversible with a targeted geriatric intervention [3]. One of the main geriatric interventions is probably physical rehabilitation with exercises. The American College of Sports Medicine (ACSM) position states that participation in regular physical activities elic- 
its a number of favorable responses that contribute to healthy aging and reduce the risk of frailty [4]. Indeed, exercise has consistently been found to improve physical function, sarcopenia, cognitive performance, and mood, which all are significant components of frailty [5-10]. Optimized exercise training has been proposed on a multi-component basis, including endurance, balance, and resistance training [11], to which recently released guidelines added a greater emphasis on high intensity exercise including muscle strengthening activities [12]. In a recent meta-analysis involving 18 interventional studies $(n=2517$ participants with age at inclusion ranged from 60 to 85 years) published from 1998 to 2009 , the authors showed that a multi-component exercise program was more effective in limiting or reducing sarcopenia than low intensity interventions [6], and, in turn, to limit adverse associated outcomes, including falls, fractures, frailty, and mortality [13-18]. But, most of interventional studies concerned in-home participants. Few studies were devoted to inpatients and the feasibility of multi-component exercise program remains unclear in this population. We aimed to assess the feasibility and the effects on extremity physical performances of a multi-component exercise program in older inpatients.

\section{Methods}

\section{Study Design and Population}

An interventional pilot study of a multi-component exercise training program (MCETP), was performed in a department of geriatric medicine (Rene Muret Hospital, Sevran, France), between June 1 to December 30, 2016.

Patients were eligible for this study if they were aged 70 and over, and if they were independent to walk. Patients with stroke, acute coronary syndrome, hip or knee intervention lasting for less than 6 months, severe heart failure and pulmonary insufficiency were excluded from this study. Informed consent was obtained from the patients before inclusion. This study was approved by the local ethics committee (CLEA, Avicenne Hospital, Bobigny, France).

\section{Clinical Data}

Demographic data (age, sex), blood pressure (mmHg), and a screening for sarcopenia which was defined in agreement with the European Working Group on Sarcopenia (EWGOS) consensus as a gait speed (measured over 10 meters) $\leq 0.8 \mathrm{~m} / \mathrm{s}$, and a reduced muscle mass as assessed by a calf circumference $<31 \mathrm{~cm}$ [19].

\section{Pre-MCETP Geriatric Assessment}

Geriatric assessment (GA) was performed at inclusion, and included the three following domains: comorbidities assessed by the cumulative illness rating scale geriatric (CIRSG); malnutrition was defined in agreement with the French nutritional guidelines as: body mass index (BMI) $<21 \mathrm{~kg} / \mathrm{m}^{2}$ and or weight loss $>5 \%$ in 1 month or $>10 \%$ in 6 months and or albumin level $<35 \mathrm{~g} / \mathrm{l}$; and cognitive impairment was defined as a mini mental state examination (MMSE) < 24/30.

\section{Physical Performances}

We performed three measures of physical performances. Rising from a chair (RC) defined as the time (in seconds) needed to stand up and sit down 5 consecutive times as fast as possible [20] Gait speed (GS) over 10 meters. Patients had to walk along a corridor with the following indication: "please begin walking at your normal pace", and after the running order: "go". GS was measured in "m/s" with a chronometer by dividing the distance in meters $(4 \mathrm{~m})$ by the time in seconds. If a participant could not walk, GS was "0" [21]. Timed Get Up and Go test (TGUG), a composite walking test that measures the time (in seconds) needed to rise from a chair, walk over 3 meters and a return to the chair [22].

\section{Intervention}

Patients were exercised 3 times a week for 12 weeks in a specifically devoted room. They were managed by a sport coach and supervised by a physician involved in geriatric medicine. Each training session comprises three 20-minutes activities, during which the patient is exercised successively for endurance, resistance, and balance. Endurance training consisted in slowly biking or walking. Resistance training consisted in exercising on strength machines specifically designed for older patients (Gamme R'Line Plus RG14, RG 20, RG 50, RG 39S, RG41).Swith small loads, joint and muscle safety protections, pneumatic resistances, and improved accessibility. Balance training consisted in both static and dynamic balance exercising. Extremity physical performances were measured at baseline (week 0, W0), after 6 (W6) and 12 (W12) training weeks. When the patients live hospital and do not want to pursue the training, the three tests were measured as well (hospital discharge).

\section{Outcome}

The primary outcome was the feasibility of a MCETP defined as percentage of refusal, abandonment ( $\leq 1$ session) and participation rate ( $>1$ session) at least $80 \%$ of sessions the patients were able to achieve without pain or any other adverse events. The secondary outcome was the effect on physical performances (RC, TGUG and GS) of MCETP.

\section{Statistical Analyses}

Categorical results are presented as counts and percentages and as means $\triangle$ standard deviations (SD) for quantitative data. Feasibility of a MCETP was estimated by percentage and 95\% confidence interval $(95 \% \mathrm{CI})$. Association between acceptation the training and clinical data was performed using t-test or Mann-Whitney test if non-normally distributed variables, for quantitative data. The Chi-2 test was used for categorical data. Self-perception of MCETP was dichotomized by moderate (included hard) vs light. A univariate mixed logistic regression was performed. Continuous variables were dichotomized based on median values. Improvement of physical performance was evaluated by paired t-test or Wilcoxon signed-rank test if non-normally distributed variables. All tests 
were two-sided at a 0.05 significance level. Analyses were carried out using R statistical software version 3.1.2.

\section{Results}

Characteristics of patients included and feasibility of MCTEP in older inpatients Clinical characteristics of patients studied are described in Table 1. Among 51 patients who were asked for, 21 refused the training, 30 (58.8\% [95\%CI: 44\%-72\%]) achieved at least one training session, including 17 (33.3\% [21\%- 48\%]) who completed more than a single session and $13(25,5 \%$ [14\%- 40\%]) who ceased the training after the first session. Patients who completed $\geq 1$ training session had better MMSE than patients who refused $(20.6 \pm 4.8$ vs $14.5 \pm 5.4 \mathrm{p}=0.007)$. Patients who abandoned the training after a single session had a significantly higher body

Table 1: Clinical characteristics of patients.

\begin{tabular}{|c|c|c|c|c|c|c|}
\hline \multirow[b]{2}{*}{ Variables } & \multirow{2}{*}{$\begin{array}{c}\text { Patients who Completed } \\
\geq 1 \text { Session } \\
n=30\end{array}$} & \multirow{2}{*}{$\begin{array}{c}\text { Patients Who } \\
\text { Refused } \\
n=21\end{array}$} & \multirow[b]{2}{*}{$P$} & \multicolumn{2}{|c|}{ Patients who Completed $\geq 1$ Session } & \multirow[b]{2}{*}{$\mathbf{P}$} \\
\hline & & & & All patients & $\begin{array}{c}\text { Patients who left after a single } \\
\text { session }\end{array}$ & \\
\hline Age (y), mean & 81.3 & 85.3 & 0.19 & 83.3 & 78.5 & 0.22 \\
\hline Gender (women) & $18(60 \%)$ & $13(62 \%)$ & 1 & $12(70.6 \%)$ & $6(46.2 \%)$ & 0.33 \\
\hline MMSE, mean & 20.6 & 14.5 & 0.007 & 21.2 & 19.75 & 0.54 \\
\hline CIRS-G total, mean & 6.5 & 6.4 & 0.92 & 7.4 & 5.1 & 0.066 \\
\hline BMI $\left(\mathrm{kg} / \mathrm{m}^{2}\right)$, mean & 26.9 & 22.8 & 0.056 & 24.6 & 32.4 & 0.023 \\
\hline
\end{tabular}

\section{Self-Perception Of MCETP}

A record about how the session was perceived was collected after $320(88.9 \%)$ sessions, $1(0.3 \%)$ was qualified hard, 105 (32.8\%) moderate and 214 (66.9\%) light. Table 2 shows selfperception of exertion according to the patients' characteristics. A MMSE $>22$, an albumin blood level $>39 \mathrm{~g} / \mathrm{L}$, an increase in mass index than patients who completed $>1$ session $32.4 \pm 9.3$ vs $24.6 \pm 5, p=0.023)$. The 17 patients who completed $>1$ session $(12$ women, $70.6 \%$ ) had a mean age of $83.4 \pm 7.5$ years, a mean MMSE score $21.2 \pm 4.6$. Most had no sarcopenia (10 of $13,76.9 \%)$ nor denutrition (12of $15,80 \%)$, while 3 only (20\%) received an additional nutritional support for denutrition. The mean associated comorbidities, as calculated with the CIRS-G was $7.4 \pm 3.3$. A total of 360 sessions were performed by these 17 patients $(82.8 \%)$. The causes for which sessions were missed were mainly due $(n=66,88 \%)$ to simultaneous conventional hospital care or shortcomings (medical consultations, difficulties with patients' transportation). Among refusals, $4(8.9 \%)$ were explained by weakness, 2 (4.4\%) by falls outside the training room during hospitalization, and the remaining 3 (6.6\%) without explanation.
TGUG performance $>20 \%$, an increase in gait speed $>15 \%$ were associated with a lower level exercise self-perception whereas an age $>80$ years was associated with a higher self-perceived exertion level. In addition, when patients were asked for their emotional perception of the training, no session was reported as unpleasant, 5 (1.6\%) were reported with a neutral responses, and 311 (98.4\%) were reported favorably.

Table 2: Factors associated with Self-perception of exertion in univariate analysis.

\begin{tabular}{|c|c|c|}
\hline Variable & OR [IC95\%] & P \\
\hline Age (>80 ans) & $0.02[0.00-0.21]$ & 0.001 \\
\hline BMI ( $\geq 25)$ & $0.52[0.06-4.75]$ & 0.031 \\
\hline MMSE (>22) & $9.62[1.22-75.9]$ & 0.55 \\
\hline Gender (Male) & $2.05[0.19-21.85]$ & 0.93 \\
\hline CIRS-G (>7) & $1.11[0.11-11.48]$ & 0.016 \\
\hline Albumin (>39) & $11.1[1.58-78.6]$ & 0.23 \\
\hline Créatinine (>70) & $4.07[0.41-39.9]$ & 0.22 \\
\hline Hemoglobin (>13.2) & $0.23[0.02-2.36]$ & 0.38 \\
\hline C Reactive protein (>4) & $0.31[0.02-4.22]$ & 0.82 \\
\hline Increase RC $(>30 \%)$ & $1.29[0.14-13.13]$ & 0.01 \\
\hline Increase in TUG $(>20 \%)$ & $10.64[1.77-63.86]$ & 0.012 \\
\hline Increase in gait speed $(>15 \%)$ & $12.60[1.75-90.76]$ & \\
\hline
\end{tabular}

\section{Improvement of Physical Performance at the End of} MCETP

Among 17 patients who attended $\geq 1$ training session, 7 completed the entire program, 2 failed to finish the training program

when data were collected, and the remaining 8 disliked further continuation of the program while discharged from hospital. Table 3 shows the changes in physical performance tests, RC, TGUG, and gait speed in the 17 patients. Significant differences $(p<0.05)$ 
were observed for all tests between W0 and W6, W0 and W6, W0, and LD (latest data). Overall the training program improved RC of $29 \%$, TGUG of $33 \%$ and gait speed of $50 \%$. Only 4 patients had no substantial improvement in gait speed, but they were no longer dependent of their stick or walker after the training.

Table 3: Improvement of physical performances at the end of MCETP: *Latest data (LD), obtained at the end of the training program, whatever the cause of its discontinuation, are compared with baseline (W0). LD is the most recent result observed between W6, W12 and the hospital discharge. LD varies from 4 to 12 weeks RC: rising from a chair test; TGUG: timed get up and go test; GS: gait speed.

\begin{tabular}{|c|c|c|c|c|c|c|c|c|}
\hline Test & Value & W0 & W6 & $\mathbf{p}$ & W12 & p & Latest data* & p \\
\hline RC & N (\%) & $17(100 \%)$ & $11(64.7 \%)$ & & $7(41.2 \%)$ & $17(100 \%)$ & 14.1 \\
\hline & Mean, s & 20 & 11.5 & $<0.001$ & 10.5 & 0.016 & $<0.001$ \\
\hline TGUG & N (\%) & $17(100 \%)$ & $11(64.7 \%)$ & & $7(41.2 \%)$ & & $17(100 \%)$ & 15.9 \\
\hline & Mean, s & 23.8 & 14.3 & 0.001 & 14.3 & $<0.001$ & 0.001 \\
\hline GS & N (\%) & $17(100 \%)$ & $11(64.7 \%)$ & & $7(41.2 \%)$ & & $17(100 \%)$ & 0.6 \\
\hline & Mean, m/s & 0.4 & 0.7 & 0.001 & 0.7 & 0.01 & $<0.001$ \\
\hline
\end{tabular}

\section{Safety of MCETP}

No training related medical event or complication occurred in the study group. Patients remained pain-free after 308 (96.6\%) sessions. One mild hip pain occurred after one session without recurrence after the subsequent sessions. Knee pains occurred in a patient during the 2 first sessions, related to a too heavy start load at the quadriceps machine. These pains disappeared after load reset during the subsequent session. A too hard cushion on the tibial crest resulted in pain 8 times. The cushion was successfully changed without further complaint.

\section{Discussion}

Although previous exercise interventions demonstrated improvements in several outcome measurements in frail older patients, large differences between studies with regards to patients included, exercise programs, program duration, and effect sizes were observed [6]. By contrast with previous studies, in which community-dwelling older persons living in residential care facilities were included mainly, our patients were recruited from an acute care and rehabilitation teaching hospital, and, in turn with a presumably more impaired state of health. Our results show that a high-intensity, short-duration rehabilitation program favorably impacts physical capacities of patients. Physical performances of our patients improved substantially, even more than what was initially expected. This was attributed to the multi-component approach the patients were exercised with and to the low load, elderly-adapted design of the training machines used. Previous studies showed favorable outcomes obtained in exercised older persons. In its meta-analysis, De Vries [6] found only small to moderate effects of physical exercise therapy on physical performances among frail older patients. He mentioned two studies with major physical effects compared with other multicomponent interventions. Jette [23] described an improvement in TUG of 1 second after a sixthmonths training in a 75-years mean age population, in which initial TUG was 13.7 seconds (7\% progress). Our study shows much better improvements: $29 \%$ with a 10 seconds difference compared with baseline. Bean et al. [24] evaluated a sixth month progressive re- sistance training intervention in 77-year-old women. They showed significant improvements in gait speed (start mean: $0.8 \mathrm{~m} / \mathrm{s}$ with $0.13 \mathrm{~m} / \mathrm{s}$ improvement, $7 \%$ ) but these results were less marked as those observed in our study (start mean: 0.4 with $0.2 \mathrm{~m} / \mathrm{s} \mathrm{im-}$ provement, 50\%).However, Bean showed better improvement in CRA (start mean measurement: $18.5 \mathrm{~s}$ with an improvement of 8 s, $43 \%$ ). Our study found a start measurement: $20 \mathrm{~s}$ with $5.9 \mathrm{~s}$ improvement, $29 \%$.

The training program developed in our study was evaluated in older patients and not in community dwelling, nursing home or home living subjects. Also, our results found worse baseline measurements for the physical tests. All our patients were frail, according to their gait speed measurement. Even if our patients pursued the training only when their health status was stabilized, we cannot affirm that the observed improvements are the exclusive effects of the multi-component exercise program and not partly related to the improvements related to simultaneous conventional hospital care. In this preliminary study, high-intensity training can be proposed safety and improves functional capacity and physical performance of frail hospitalized older patients. These results have to be confirmed in a prospective, randomized controlled trial to follow.

\section{Acknowledgment}

We thank Mathieu Alcotte, Sandrine Cece, Bernadette Moreau and Gina Rakotovao for their great involvement in the program.

Author Contribution: All authors provided critical intellectual interpretation and manuscript revision and read and approved the final manuscript.

Conflict of Interest: The authors have no conflicts of interest to declare. Sponsor's Role: None.

Ethical Standards: The experiments comply with the current laws of the country.

\section{References}

1. QianLi Xue (2011) The Frailty Syndrome Definition and Natural History. Clin Geriatr Med 27(1): 1-15. 
2. Fried LP, Tangen CM, Walston J, Newman AB, Hirsch C, et al. (2001) Evidence for a phenotype. J Gerontol a Biol Sci Med Sci. 56(3): 146-156.

3. Trevisan C, Veronese N, Maggi S, Baggio G3, Toffanello ED, et al. (2017) Factors Influencing Transitions Between Frailty States in Elderly Adults: The Progetto Veneto Anziani Longitudinal Study. J Am Geriatr Soc 65(1) 179-184.

4. Chodzko Zajko WJ, Proctor DN, Fiatarone Singh MA, Minson CT, Nigg CR, et al. (2009) American College of Sports Medicine, American College of Sports Medicine position stand. Exercise and physical activity for older adults. Med Sci Sports Exerc 41(7): 1510-1530.

5. Theou O, Stathokostas L, Roland KP, Jakobi JM, Patterson C, et al. (2011) The Effectiveness of Exercise Interventions for the Management of Frailty: A Systematic Review. J Aging Res. 569194.

6. De Vries NM, van Ravensberg CD, Hobbelen JS, Olde Rikkert MG, Staal JB, et al. (2012) Effects of physical exercise therapy on mobility, physical functioning, physical activity and quality of life in community-dwelling older adults with impaired mobility physical disability and/or multimorbidity a meta-analysis. Ageing Res Rev 11(1): 136-149.

7. Chin A Paw MJ, van Uffelen JG, Riphagen I, van Mechelen W (2008) The functional effects of physical exercise training in frail older people : a systematic review. Sports Med 38(9): 781-793.

8. Daniels R, van Rossum E, De Witte L, Kempen GI, van den Heuvel W, et al. (2008) Interventions to prevent disability in frail community-dwelling elderly: a systematic review. BMC Health Serv Res 8:278.

9. Hubbard RE, Fallah N, Searle SD, Arnold Mitnitski, Kenneth Rockwood, et al. (2009) Impact of exercise in community-dwelling older adults. PLoS One 4(7): e6174.

10. Peterson MJ, Giuliani C, Morey MC, Carl F Pieper, Kelly R Evenson, et al. (2009) Physical activity as a preventative factor for frailty: the health, aging, and body composition study. J Gerontol A Biol Sci Med Sci. 64(1): 61-68.

11. Pate RR, Pratt M, Blair SN, Haskell WL, Macera CA, et al. (1995) Physical activity and public health. A recommendation from the Centers for Disease Control and Prevention and the American College of Sports Medicine. JAMA 273(5): 402-407.

12. Nelson ME, Rejeski WJ, Blair SN, Duncan PW, Judge JO, et al. (2007) Physical activity and public health in older adults: recommendation from the American College of Sports Medicine and the American Heart Association. Med Sci Sports Exerc 39(8): 1435-1445.

\section{ISSN: 2574-1241}

DOI: 10.26717.BJSTR.2019.14.002558

Véronique François. Biomed J Sci \& Tech Res

This work is licensed under Creative Commons Attribution 4.0 License

Submission Link: https://biomedres.us/submit-manuscript.php
13. Beaudart C, Rizzoli R, Bruyere O, Jean-Yves Reginster, Emmanuel Biver, et al. (2014) Sarcopenia: Burden and challenges for Public Health. Archives of Public Health. Arch Public Heal 72:45.

14. Rizzoli R, Reginster JY, Arnal JF, Bautmans I, Beaudart C, et al. (2013) Quality of life in sarcopenia and frailty. Calcif Tissue Int. 93: 101-120.

15. Lauretani F, Russo CR, Bandinelli S, Bartali B, Cavazzini C, et al. (2003) Age-associated changes in skeletal muscles and their effect on mobility: an operational diagnosis of sarcopenia. J Appl Physiol 95(5): 1851-1860.

16. Visser M, Schaap LA (2011) Consequences of sarcopenia. Clin Geriatr Med 27(3): 387-399.

17. Lang T, Streeper T, Cawthon P, Baldwin K, Taaffe DR, et al. (2010) Sarcopenia: etiology clinical consequences intervention and assessment. Osteoporos Int 21(4): 543-559.

18. Landi F, Cherubini A, Cesari M, R Calvania, MTosato e,t al. (2016) Sarcopenia and frailty: From theoretical approach into clinical practice. Eur Geriatr Med 7(3): 197-200.

19. CruzJentoft AJ, Baeyens JP, Bauer JM, Boirie Y, Cederholm T, et al. (2010) Sarcopenia: European consensus on definition and diagnosis: Report of the European Working Group on Sarcopenia in Older PeopleAge Ageing. Jul 39(4): 412-423.

20. Malmstrom TK, Miller DK, Simonsick EM, Ferrucci L, Morley JE, et al. (2016) SARC-F: a symptom score to predict persons with sarcopenia at risk for poor functional outcomes. J Cachexia Sarcopenia Muscle. 7(1): 28-36.

21. (2010) Rehabilitation Measures Team. Rehab Measures 10 Meter Walk Test Rehabilitations Database.

22. Podsiadlo D, Richardson S (1991) The timed up-and-go: a test of basic functional mobility for frail elderly persons. J Am Geriatr Soc 39 (2): 142-148.

23. Jette AM, Lachman M, Giorgetti MM, S F Assmann, B A Harris, et al. (1999) Exercise--it's never too late: the strong-for-life program. Am J Public Health 89(1): 66-72.

24. Bean JF, Herman S, Kiely DK, Frey IC, Leveille SG, et al. (2004) Increased Velocity Exercise Specific to Task (InVEST) training: a pilot study exploring effects on leg power, balance, and mobility in communitydwelling older women. J Am Geriatr Soc 52(5): 799-804.

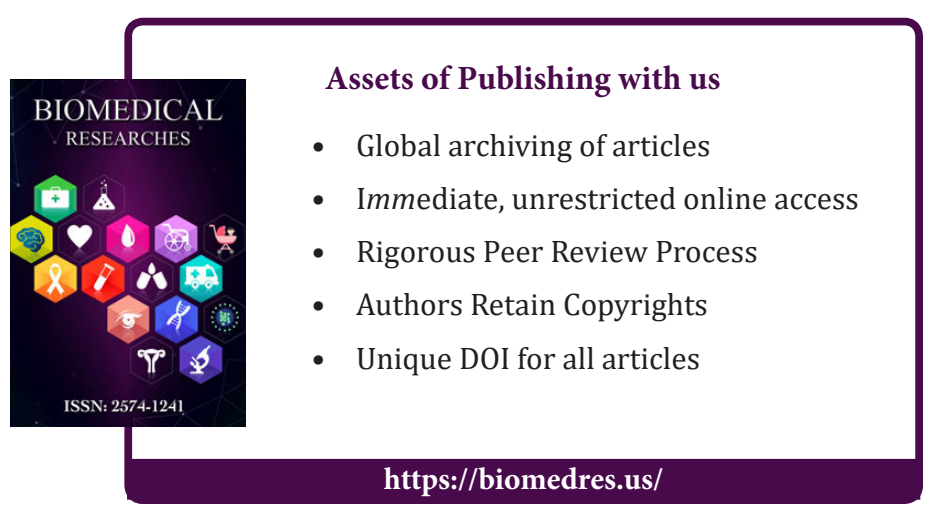

